\title{
WSN Based Air Pollution Monitoring System
}

\author{
Amol R. Kasar \\ Department of Computer Engg, \\ MIT Academy Of Engg. \\ Pune University, \\ Pune,India
}

\author{
Dnyandeo S. Khemnar \\ Department of Computer Engg, \\ MIT Academy Of Engg. \\ Pune University, \\ Pune, India
}

\author{
Nagesh P. Tembhurnikar \\ Department of Computer Engg, \\ MIT Academy Of Engg. \\ Pune University, \\ Pune, India
}

\begin{abstract}
Air pollution monitoring is extremely important as air pollution has a direct impact on human health and environment. In this paper we introduce a wireless sensor network system for participatory air pollution monitoring. The traditional air quality monitoring system, controlled by the Pollution Control Department, is extremely expensive. Analytical measuring equipment is costly, time and power consuming. In contrast to traditional air pollution monitoring stations, we present the design, implementation, and evaluation of low power, low cost WSN based Air Pollution Monitoring System which provides real time monitoring of polluted materials at proper locations by using distributed (real time) air pollution monitoring systems.
\end{abstract}

Keywords: Air Pollution, AtMega16 microcontroller, MG811 Sensor ,MQ6 Sensor,MQ135 Sensor, Real Time, ZigBee, WSN

\section{INTRODUCTION}

Air pollution is one of the most important factors affecting the quality of life and the health of the increasingly urban population of industrial societies. In many cities, the air is polluted by emissions from sources such as cars and trucks, power plants, and manufacturing processes. When gases and particles from those activities accumulate in the air in high enough concentrations, they can be harmful for human health, an environment. Often, terrain and meteorological conditions complicate air quality issues in the area. Although the national trend is toward better outdoor air quality, there are some urban areas in which no improvement has taken place. Concentrations of outdoor air pollutants vary from day-to-day and even during the course of a day.

For health protection, the public needs timely information about air quality and other factors (e.g., weather conditions) that affect it. An access to air quality forecasts allows residents to reduce their exposure when the pollutant concentrations are high. This is important particularly to people who are sensitive to certain pollutants' harmful effects. For example, people with asthma may be sensitive to groundlevel ozone and sulphur dioxide. The major motivation behind our study and the development of the system is to help the government to devise an indexing system to categories air pollution in India. The project is to build an air pollution monitoring system, so a detection system for multiple information of environment is designed in this project. This project is built for low cost, quick response, low maintenance, ability to produce continuous measurements. The main goal of this project is to monitor the air pollution, hazardous gases and increase awareness about pollution by using air pollution monitoring system. Present state of the air quality control in almost all industrial centers in our country is based on taking samples one or few times a day, which means that there is no information about time distribution of polluted materials intensity during day. This is the main disadvantage of such
system.In the area, there are two methods to use to monitor air pollution at present. The one is passive sampling (nonautomatic), and the other is continuous online monitoring (automatic). The advantage of the passive sampling method lies in that the monitor equipment is simple and inexpensive, but it can only get on-site monitoring parameters in a certain period, cannot provide real-time values. Meanwhile, the results of monitoring effect by the man factor largely and it will seriously damage the health of the monitoring man in the site of high concentration of harmful substances.

The procedure of continuous monitoring method is as follows: use sensors to monitor the parameters, and then send to the control center by network. The way of data transfer include both wired and wireless. The wired way usually uses public telephone network, or fiber-optic to realize data transmission. Although this method is stable and reliable, with high speed of data transmission, but the shortcomings of the method is also obvious in a wide and dynamic range. With the rapid development of communication technology, network technology and remote sensing technology, there is a trend that air pollution monitoring system is often designed in wireless mode. At present, the wireless mode in air pollution monitoring system includes GSM, GPRS, etc. But these modes are high cost in both installation and maintenance, and complexity. In the other hand, Wireless sensor network have been rapidly developed during recent years. Starting from military and industrial controls, its advantages include the liability, simplicity, and low cost. Based on these advantages, it is now being applied in environmental monitoring. In air pollution monitor applications, we have designed a WSN based air pollution monitoring system using ZigBee networks for City. They focus on implementation of air pollution monitoring system, and developed an integrated wireless sensor board which employs $\mathrm{CO} 2, \mathrm{NO} 2 / \mathrm{NH} 3$ temperature sensor, atmega16 micro-controller, database server and a ZigBee module. 


\section{System Overview}

\subsection{Proposed System}

Figure 1:Proposed system scenario

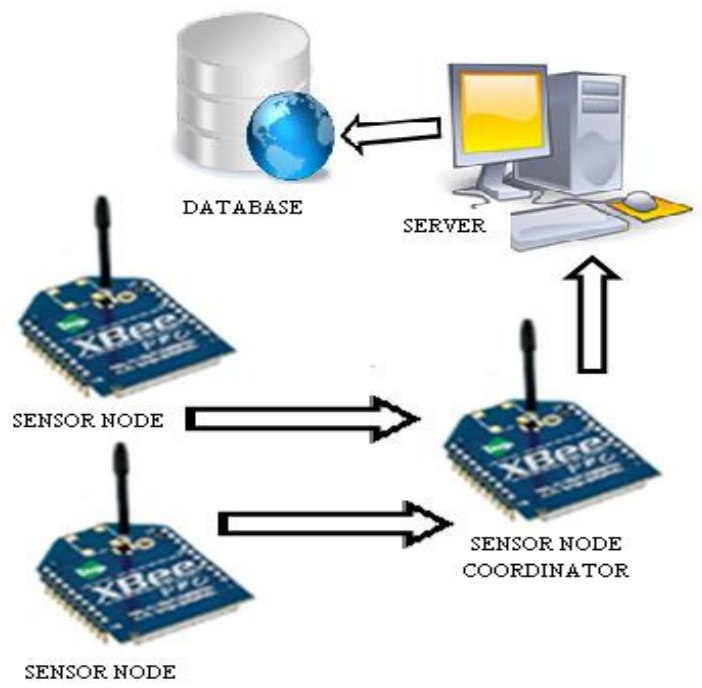

The working of proposed Air pollution monitoring system as follows:

1. Develop architecture to define nodes and their interaction.

2. Collect air pollution readings from a region of interest.

3. Collaboration among thousands of nodes to collect readings and transmit them to a gateway, all the while minimizing the amount of duplicates and invalid values.

4. Use of appropriate data aggregation to reduce the power consumption during transmission of large amount of data between the thousands of nodes.

5. Visualization of collected data from the WSN using statistical and user-friendly methods such as tables and line graphs.

6. Provision of an index to categorize the various levels of air pollution, with associated colors to meaningfully represent the seriousness of air pollution.

7. Generation of reports on a daily or monthly basis as well as real-time notifications during serious states of air pollution for use by appropriate authorities

\subsection{Hardware Architecture}

The proposed system is designed by integrating the following hardware modules shown in Fig. 2. As the figure shows, the system consists of a ATMEGA16 microcontroller integrated with a sensor array using analog ports. The hardware unit is also connected to a GPS module and a ZigBee-Modem using the RS-232 interface. Each of these components is described in the following

\subsubsection{ATMEGA16 microcontroller}

The ATMEGA16 microcontroller is the main component of a pollution detection unit. The operating system that runs inside the chip coordinates the substances measurement process, the acquisition of the GPS coordinates and the data transmission

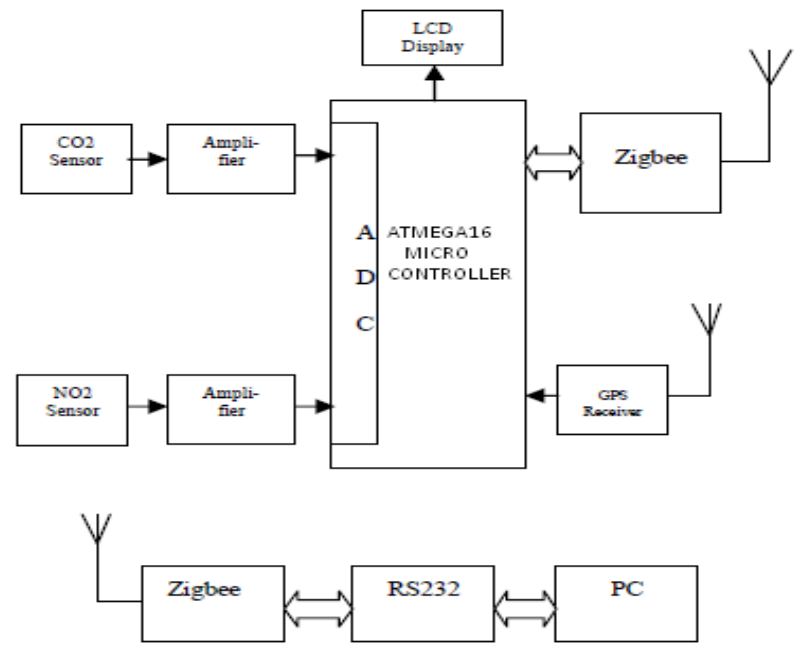

Figure 2: System hardware basic building blocks

to the central server. The microcontroller is mounted on a development board that provides an RS232 serial communication to the ZigBee modem and ZigBee receiver and a parallel connection to the gas sensors. The connection between the gas sensors and the ATMEGA16 microcontroller can't be made directly because of the very small output voltages provided by the sensors (mA).This problem is solved by using auxiliary electronic circuits for signal conversion like OA (Operational Amplifiers) and transistors.(see Figure 2)

\subsubsection{Sensors Array}

The sensor array consists of two air pollutions sensors including Carbon Dioxide (CO2), Nitrogen Dioxide (NO2). As Table I shows, the resolution of these sensors is sufficient for pollution monitoring. Each of the above sensors has a linear current output in the range of $4 \mathrm{~mA}-20 \mathrm{~mA}$. The $4 \mathrm{~mA}$ output corresponds to zero-level gas and the $20 \mathrm{~mA}$ corresponds to the maximum gas level. A simple signal conditioning circuit is designed to convert the $4 \mathrm{~mA}-20 \mathrm{~mA}$ range into $0-5 \mathrm{~V}$ to be compatible with the voltage range of the built-in analog-to digital converter in the ATMEGA16 microcontroller. (see Figure 1,2)

\subsubsection{ZigBee Modules}

In this paper, two types ZigBee modules are used to organize a network for air pollution monitoring system. The network is controlled by devices called the ZigBee coordinator modem (ZCM). The ZCMs are responsible for collecting data and maintaining the other devices on the network, and all other devices, known as ZigBee end devices (ZED), directly communicate with the ZCM. The ZigBee module is hardware platform of wireless device. The modules realize the basic function of Physical and MAC layer, such as transmit and receive, modulation and demodulation, channel and power control. They operate at $2.4 \mathrm{GHz}$ frequency ISM band wireless communication. The modules include a digital direct sequence spread spectrum base band modem and an effective data rate of $250 \mathrm{kbps}$. They employ the EM2420 $2.4 \mathrm{GHz}$ radio frequency transceiver and the ATMEL 8-bit AVR microcontroller. They also exhibit a nominal transmit of $1.5 \mathrm{dBm}$ and a receive sensitivity of $-92 \mathrm{dBm}$ When powered at 
$3.0 \mathrm{~V}$, the modules draw $31.0 \mathrm{~mA}$ in transmit mode and $28 \mathrm{~mA}$ in receive mode. When the entire module is in sleep mode, the current draw is reduced to approximately $10 \mathrm{uA}$.(see figure $1,2)$

Table 1. Sensor Specification

\begin{tabular}{|l|l|l|}
\hline Sensor & C02 & N02 \\
\hline Resolution (ppm) & $<1.5$ & $<0.02$ \\
\hline Resp. time (t90)(s) & $<60$ & $<60$ \\
\hline Op. range (ppm) & $0-10000$ & $0-20$ \\
\hline Operating life (yrs) & $>2$ & $>2$ \\
\hline Diameter (mm) & 20 & 20 \\
\hline
\end{tabular}

\subsubsection{Central Server}

The Central-Server is an off-the-shelf standard personal computer with accessibility to the Internet. The Pollution Server is connected to the ZigBee-Modem via RS-232 communication standard. The air pollution information sent from each ZED are collected to ZCM. And then the data are saved to database of central server.(see figure 1)

\section{ZigBee Standard}

The ZigBee is the new short range, low power, and low data rate wireless networking technology for many applications. It is best specified the bottom three layers (Physical, Data Link, and Network), as well an Application Programming Interface (API) based on the 7-layer OSI model for layered communication systems. Figure-3 shows the layered protocol architecture adopted by the alliance. It should be noted that the ZigBee Alliance chose to use an already existing data link and physical layers specification. These are the recently published IEEE 802.15.4 standards for low rate personal area networks.(see figure 3)

A communication network is composed of many nodes, each of which can transmit and receive data over communication links, wireless or cabled supports network topologies. The ZigBee network layer supports star, tree and mesh topologies. The ZigBee coordinator is responsible for initiating and maintaining the devices on the network, and all other devices, known as end devices, directly communicate with the ZigBee coordinator. In mesh and tree topologies, the ZigBee coordinator is responsible for starting the network and for choosing certain key network parameters but the network may be extended through the use of ZigBee routers. In tree networks, routers move data and control messages through the network using a hierarchical routing strategy.(see figure 4)

The IEEE 802.15.4 standard defines three frequency bands of operation: $868 \mathrm{MHz}, 916 \mathrm{MHz}$ and the $2.4 \mathrm{GHZ}$ bands for ZigBee. $2.4 \mathrm{GHz}$ bands are used the most commonly available wireless communication products throughout the world because of ISM (Industrial, Scientific, Medical) band. In addition this band offers the highest achievable data rate of $250 \mathrm{Kbps}$ and 16 channels between $2.4 \mathrm{GHz}$ and $2.4835 \mathrm{GHz}$ at the physical layer. Typical transmission distances are within the range from 30 meters in an indoor non-line of sight environment to over 100 meters in a line of sight environment. But problems related a range can be solved through applying routing algorithm at the network layer.(see figure 5)

Figure 3: ZigBee protocol stack for layered wireless communication

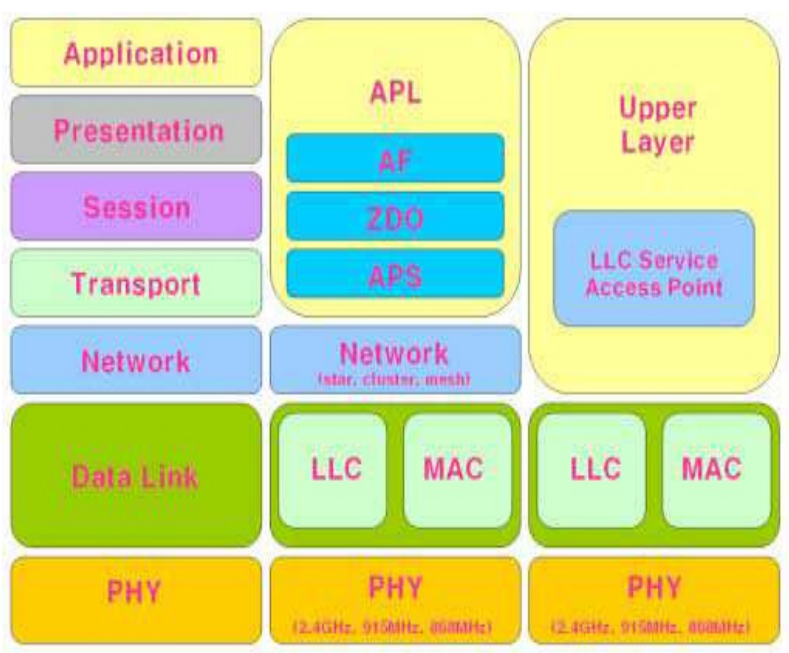

Figure 4: ZigBee network topologies

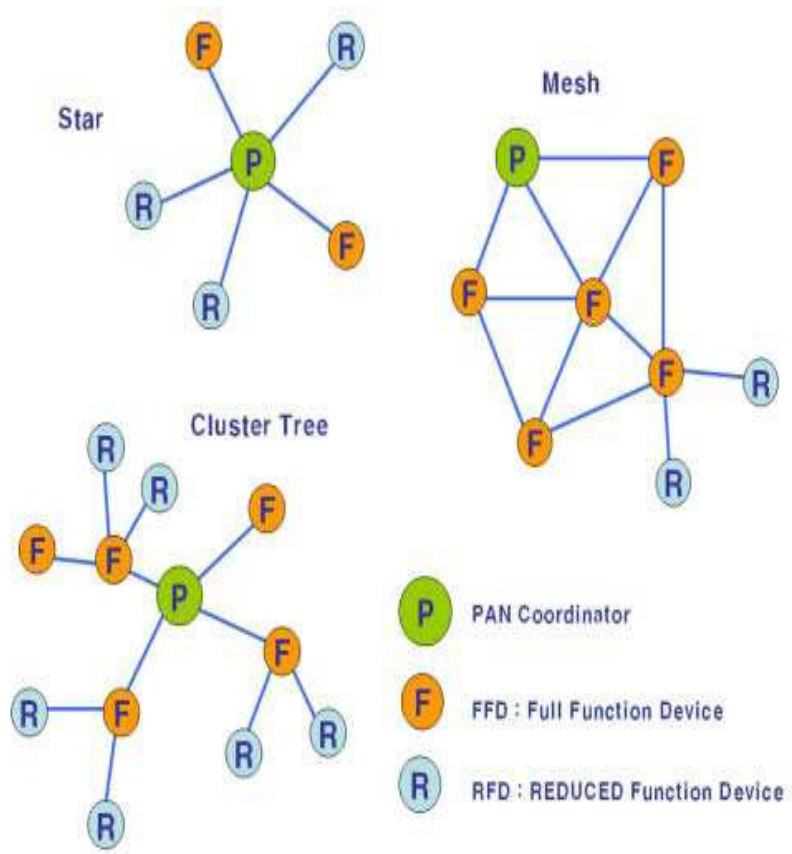

Although defined as $25 \mathrm{~mW}$ in the world, transmit output power of ZigBee is limited within $10 \mathrm{~mW}$. Therefore ZigBee 
modules employ dipole type antenna to increase gain of antenna.

Figure 5: Frequency Bands Used for ZigBee

\begin{tabular}{llllllll} 
Frequency & Band Coverage & Data rate & Ch & $\begin{array}{c}\text { Rx } \\
\text { Sensitivity Modulat }\end{array}$ \\
$2.4 \mathrm{GHz}$ & ISM & Worldwide & $250 \mathrm{Kbps}$ & 16 & $-85 \mathrm{dbm}$ & 0-QPs \\
\hline $868 \mathrm{MHz}$ & Europe & $20 \mathrm{Kbps}$ & 1 & $-92 \mathrm{dbm}$ & BPS \\
\hline $915 \mathrm{MHz}$ & ISM Americas & $40 \mathrm{Kbps}$ & 10 & $-92 \mathrm{dbm}$ & BPSH
\end{tabular}

\section{AIR Quality}

In a general way, it is possible to describe the atmosphere as a very thin gaseous film, where all the meteorological phenomena that regulate the human life occur. Filled with a great diversity of molecules (Table I), the atmosphere performs, at the same time, a role of protection and regulation. Air pollution can have various definitions. According to, "air pollution means the presence, within the external atmospheres, of one or more contaminants, or its combination in quantities or with a temporal duration that can become harmful to human life, vegetable, animal or goods.

The air contaminants include smokes, steams, paper hashes, dusts, soot, carbonic smokes, gases, fogs, radioactive material or toxic chemical products." Certain atmospheric pollutants react with each other creating others pollutants called secondary pollutants. The dissociation, trough the sun's effect, of volatiles organic compounds, carbon monoxide and nitrogen oxide, produced by automobile's motors, lead to the formation of ozone, essentially during the summer, whetemperature reaches higher levels.

Table 2. Average composition of pure air

\begin{tabular}{|l|l|l|}
\hline Element & Symbol & Proportion \\
\hline Nitrogen & $\mathrm{N} 2$ & $78.084 \%$ \\
\hline Oxygen & $\mathrm{O} 2$ & $20.946 \%$ \\
\hline Argon & $\mathrm{Ar}$ & $0.943 \%$ \\
\hline $\begin{array}{l}\text { Carbon } \\
\text { dioxide }\end{array}$ & $\mathrm{C02}$ & $340 \mathrm{ppm}$ \\
\hline Neon & $\mathrm{Ne}$ & $18.18 \mathrm{ppm}$ \\
\hline Helium & $\mathrm{He}$ & $5.24 \mathrm{ppm}$ \\
\hline Methane & $\mathrm{CH} 4$ & $1.5 \mathrm{ppm}$ \\
\hline Krypton & $\mathrm{Kr}$ & $1.14 \mathrm{ppm}$ \\
\hline $\begin{array}{l}\text { Hydrogen } \\
\mathrm{H}\end{array}$ & $0.50 \mathrm{ppm}$ \\
\hline $\begin{array}{l}\text { Oxide } \\
\text { Nitrous }\end{array}$ & $\mathrm{N} 2 \mathrm{O}$ & $0.40 \mathrm{ppm}$ \\
\hline Xenon & $\mathrm{Xe}$ & $0.09 \mathrm{ppm}$ \\
\hline
\end{tabular}

Air pollution has dramatic consequences for human health, leading to respiratory problems and even death [6] and for the environment like the greenhouse effect, acid rains and ozone layer reduction.

The European Community has dedicated special attention to the problem of the most representative pollutants concentration, such as the case of Carbon Monoxide (CO), Nitrogen Dioxide (NO2), Sulphur Dioxide (SO2), Ozone (O3) and particles of $10 \mu \mathrm{m}$ or less (PM10) and special Regulations have been produced. Although the Carbonic Dioxide (CO2) isn't considered a pollutant, its concentration has also to be quantified, due to importance of this gas to the planet's ecosystems.

The system presented here is capable of measuring the following gases in the atmosphere:

4.1 Carbon Dioxide (CO2) - Carbon Dioxide is a gas essential to life in the planet, because it is one of the most important elements evolving photosynthesis process, which converts solar into chemical energy. The concentration of $\mathrm{CO} 2$ has increased due mainly to massive fossil fuels burning. This increase makes plants grow rapidly. The rapid growth of undesirable plants leads to the increase use of chemicals to eliminate them.

4.2 Sulphur Dioxide (SO2) - Sulphur Dioxide is a colorless gas, detectable by the distinct odor and taste. Like $\mathrm{CO} 2$, it is mainly due to fossil fuels burning and to industrial processes. In high concentrations may cause respiratory problems, especially in sensitive groups, like asthmatics. It contributes to acid rains.

4.3 Nitrogen Dioxide (NO2) - Nitrogen Dioxide is a brownish gas, easily detectable for its odor, very corrosive and highly oxidant. It is produced as the result of fossil fuels burning. Usually NO thrown to the atmosphere is converted in $\mathrm{NO} 2$ by chemical processes. In high concentrations, NO2 may lead to respiratory problems. Like SO2, it contributes to acid rains.

4.4 Air-Quality-Index: Function to convert the raw pollutant level received from each node to pollution standards called air quality index (AQI) using the formula.

$\mathrm{AQI}=($ Pollution Level/Pollution Standard $) * 100$

The pollution standard is defined according the air quality standards of a particular region. For example, the pollutant standard for $\mathrm{CO}, \mathrm{NO} 2$, and $\mathrm{SO} 2$ are 20, 0.15, and $0.13 \mathrm{ppm}$, respectively. Following the air quality is divided into four categories. An index value of $0-100$ corresponds to clean air, 101-125 represent light pollution, 126-150 signify four categories. An index value of $0-100$ corresponds to clean air, 101-125 represent light pollution, 126-150 signify significant pollution, and above 150 means heavy pollution. In summary, the Air Quality-Index function returns a pollution category from the raw pollutant data. 


\section{Conclusion}

A WSN Based Air Pollution Monitoring System was designed, implemented and tested using the wireless sensor network. The system is used to collect pollutant gases such as $\mathrm{CO} 2, \mathrm{NO} 2$, and $\mathrm{SO} 2$ from environment. The pollution data from various mobile sensor arrays is transmitted to a central several that make this data available to government authority. The data shows the pollutant levels and their conformance to local air quality standards. The system also uses the AQI to evaluate the level of health concern for a specific area. It also associates meaningful and very intuitive colors to the different categories, thus the state of air pollution can be communicated to the user very easily.(see table 2 )

\section{ACKNOWLEDGMENTS}

The moment representing this project paper, we are grateful to all the respected professors for extending their valuable guidance to us. This was not just due to the efforts made by us but also the valuable guidance \& facilities provided by our esteemed institution. Thus giving us an opportunity to amalgate our theoretical knowledge into presentation of project paper.with respect and deep gratitude we express our thanks to Prof. Pramod Ganjewar and Mrs. Uma Nagraj Computer Engineering (HOD) .We are thankful in particular to Prof. ShitalKumar Jain (Senior lecturer in Computer dept.) for his time to time guidance, without which the completion of this project would have been impossible.

Our colleagues, who have been supportive throughout, are equally appreciable and deserving of our gratitude.

\section{REFERENCES}

[1]. N. Kularatna and B.H. Sudantha, "An environmental air pollution monitoring system based on the IEEE 1451 standard for low cost requirements," IEEE Sensors J., vol. 8, pp. 415-422, Apr. 2008.

[2]. Q. Cao, T. He, L. Fang, T. Abdelzaher, J. Stankovic, and S. Son, "Efficiency Centric Communication Model for
Wireless Sensor Networks", in Proceedings of IEEE INFOCOM, pp. 1- 12, 2006.

[3]. Xu.N. "A Survey of Sensor Network Applications,"EEE Communications Magazine, Vol. 40, No.8, pp. 102-114, 2002.

[4]. Martinez, K., Hart, J. K., Ong, R., "Environmental Sensor Networks," IEEE Computer, Vol. 37, No. 8, pp. 50-56.

[5]. Nikheel A. Chourasia, Surekha P. Washimkar," ZigBee Based Wireless Air Pollution Monitoring" International Conference on Computing and Control Engineering (ICCCE 2012), 12 \& 13 April, 2012

[6]. R. Rajagopalan and P.K. Varshney, "Data-Aggregation Techniques in Sensor Networks: A Survey," IEEE Communication Surveys and Tutorials, Vol. 8 (4), pp. 48-63, December 2006

[7]. Mainwaring, A., Polastre, J., Szewczyk, R., Culler, D., Anderson, J. "Wireless Sensor Networks for Habitat Monitoring," ACM International Workshop on Wireless Sensor Networks and Applications, EUA.

[8]. F. Tsow, E Forzani, A. Rai, R. Wang, R. Tsui, S. Mastroianni, C. Knobbe, A. J. Gandolfi, and N. J. Tao, "A wearable and wireless sensor system for real-time monitoring of toxic environmental volatile organic compounds," IEEE Sensors J., vol. 9, pp. 1734-1740, Dec. 2009.

[9]. Y.J. Jung, Y.K. Lee, D.G. Lee, K.H. Ryu, and S. Nittel, "Air pollution monitoring system based on geosensor network," in Proc. IEEE Int. Geoscience Remote Sensing Symp., 2008, vol. 3, pp. 1370-1373.

[10]. W. Chung and C.H. Yang, "Remote monitoring system with wireless sensors module for room environment," Sens. Actuators B, vol. 113 no. 1, pp. 35-42, 2009 